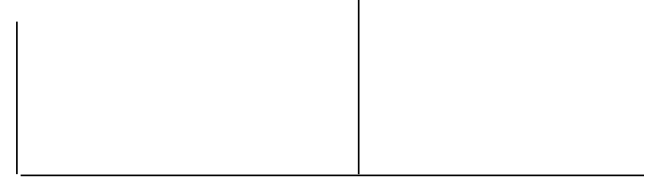

Rev. Latinoam. Psicopat. Fund., VIII, 1, 40-53

\title{
Uma vida que se esvai no Parkinson
}

\author{
Eliane Michelini Marraccini
}

A doença de Parkinson é uma síndrome neurológica de evolução lenta e progressiva que emerge na idade madura e velhice. A crescente debilitação física contrasta com a manutenção da integridade mental, na maioria dos pacientes até o fim da vida. Nessa enfermidade incurável, que costuma perdurar por longos anos, surgem importantes reações físicas diante da progressiva incapacitação, com profundos reflexos na subjetividade do paciente. Este trabalho refere-se ao atendimento de uma paciente, acompanhada em seu processo de conscientização e elaboração da irreversibilidade da doença. Ao final,é ressaltada a intrínseca articulação somatopsíquica, com destaque para a depressão na acentuação dos sintomas parkinsonianos.

Palavras-chave: Doença de Parkinson, depressão, subjetividade, psicoterapia não convencional 
Quando veio ao meu encontro, a voz de Lia era entrecortada por um choro sentido que quase a impedia de falar do sofrimento com a doença que vinha enfrentando desde os 56 anos. A doença de Parkinson chegara à sua vida muito precocemente, somando-se a ela a impossibilidade em receber a medicação mais indicada para atenuar seus sintomas pela falta de dopamina. Como ocorre com alguns pacientes, Lia apresentava reações colaterais como náuseas e vômitos quando ingeria a levodopa ou L-dopa, matéria-prima da medicação por excelência para controlar o avanço dessa síndrome neurológica progressiva e incurável.

Lia realizara psicoterapia anteriormente, ainda com cerca de quarenta anos, pela "crise enfrentada com o crescimento dos filhos". Talvez tenha sido esse um ponto inicial na transferência de Lia, pois fora a uma palestra que realizei sobre a crise feminina nessa etapa da vida. Ao final, veio ao meu encontro, procurando alguém que, em seu imaginário, poderia saber algo sobre o sofrimento vivido, não apenas no passado, mas em seu presente penoso e em torno do futuro incerto portando mal de Parkinson. Ansiava por um espaço de escuta para falar sobre o mal que tomava seu corpo e a ameaçava com a imobilização para a vida.

Aceitei-a como paciente acreditando que essa poderia ser uma experiência importante para ambas. Enfrentaríamos juntas uma penosa realidade. Tendo a psicanálise como retaguarda teóricoclínica, já se antecipava que este não seria um atendimento convencional.

Há cerca de seis anos atendo-a semanalmente, tendo acompanhado de perto o avançar da doença, minando progressivamente sua disposição física e mental. Em alguns períodos críticos, mantive contato com a família e alguns dos profissionais que a vêm assistindo: neurologistas, fonoaudiólogos, fisioterapeutas, nutricionistas e assistentes de enfermagem.

Quando iniciamos, Lia tinha sessenta anos e há quatro apresentara os primeiros sintomas. Além de múltiplos especialistas 
consultados, neurologistas alopatas e homeopatas, ela já enfrentara uma cirurgia cerebral com o objetivo de deter alguns sintomas parkinsonianos e retardar o aparecimento de outros. O aparente êxito dessa primeira intervenção fez com que, algum tempo após o início da psicoterapia, Lia decidisse enfrentar a palidotomia no outro hemisfério cerebral. Cirurgia bravamente empreendida, sendo depositária de enorme esperança. No entanto, essa cirurgia lesiva do núcleo pálido interno, que segundo Grossmann (1998) apresenta risco de complicações em uma a cada dez intervenções, foi devastadora para seu estado físico e emocional. Com seqüelas na fala e na marcha, algumas temporárias e outras permanentes, Lia resolveu renunciar ao procedimento cirúrgico de implantação de marcapasso cerebral, pela incerteza quanto à melhora dos sintomas que tanto a afligiam. A partir de então, Lia certificou-se da irreversibilidade de sua doença, com todo o sofrimento que não cessou de acompanhá-la.

Casada há mais de quatro décadas, seu marido fora acometido de infarto aos cinqüenta anos, a implantação de cinco pontes de safena tendo lugar pouco tempo depois do início dos sintomas parkinsonianos de Lia. O grande apoio representado pelo marido e o temor de perdê-lo foram sendo cada vez mais angustiantes para Lia, em sua progressiva dependência. $O$ filho mais velho, cujo escritório está sediado na residência dos pais, depende ainda de alguma ajuda financeira para sustentar esposa e duas filhas. O segundo filho, usuário de drogas e álcool, não tem trabalho sistemático. O relacionamento que mantém com os familiares é marcadamente agressivo, e Lia, especialmente, ressente-se disso. A filha foi diagnosticada diabética pouco tempo antes da doença de Lia, enfrentando dificuldades constantes em sua vida profissional e amorosa. $O$ filho caçula é quem melhor veio desenvolvendo sua vida social e amorosa, tendo buscado independência em atividade profissional antes mesmo de se formar. É com quem Lia sempre manteve o melhor relacionamento, por ele sendo atendida de forma carinhosa, embora sem se envolver com muita freqüência na rotina de cuidados que a mãe necessita. Apesar de idade para serem independentes, moram todos com os pais, à exceção do filho casado.

A dinâmica familiar e as dificuldades emocionais de cada membro chamam atenção para algo que os une a ponto de não se "soltarem" para a vida, mantendoos "paralisados", em condição de interdependência e relacionamento problemático. A profissão de médico anestesista do marido e a doença incapacitante de Lia parecem enovelar-se nessa trama de imo bilidade e dependência que compromete a todos, gerando sintomas que se expressam no soma e na psique. A doença de Lia tem sido um pólo catalisador da atenção da família, todos se concentrando no mal de Parkinson, impossibilitados de lidar quer com as conseqüências mais profundas desse quadro, quer com as implicações da subjetividade de cada um 
em tal panorama familiar. Lia está cercada de pessoas e cuidados, mas não encontra com quem compartilhar seu sofrimento. Sentimentos de solidão, isolamento e desamparo são marcantes em seu discurso, e com certeza Lia não é a única que os experimenta.

A irmã de Lia é importante apoio emocional para ela, mas, por residir em outra cidade, o contato é mais esparso do que gostariam. O pai já havia falecido há muitos anos e a mãe se encontrava internada em clínica de repouso aos 94 anos, vindo a falecer pouco depois de iniciada a psicoterapia. Lia sofreu bastante com a progressiva senilidade e debilitação materna e antevia o que sua própria doença poderia lhe reservar. Nem os genitores nem demais familiares de Lia haviam sido acometidos pelo mal de Parkinson, o que a fazia se sentir ainda mais inconformada com esse destino pessoal. Sentia-se confusa e angustiada por desconhecer a causa de ser portadora desse mal, e buscava algo que lhe fizesse sentido. E além do mais, dada a incerteza sobre como se daria a evolução da própria doença, era como se o destino a deixasse em suspenso, aguardando para conferir como se daria sua própria derrota.

Conforme descreveu uma paciente, fundadora da Associação Brasil Parkinson: "As respostas incertas para todas as perguntas e dúvidas talvez sejam a pior parte para o neoparkinsoniano" (Grossmann, 1998, p. 38). E sobretudo pelo fato de o intelecto em geral permanecer íntegro até o fim da vida, o paciente acompanha com dolorosa consciência as perdas sofridas.

Muitos parkinsonianos têm a emoção à flor da pele. Quando estão tensos é preciso que todos aqueles que o cercam tenham um pouco de paciência. Há que se entender que não é fácil para alguém necessitar da ajuda de outros para fazer determinadas coisas que antes fazia sozinho. Pode ficar irritado, frustrado ou emotivo, com alguma incapacidade de ação. Por outro lado, também é difícil conviver com alguém que só vive se lamentando. Nunca sabemos se o que fazemos hoje a determinada hora poderá ser repetido no dia seguinte (ibid., p. 109).

Algumas vezes se fizeram necessárias reuniões familiares, marido e filhos comparecendo prontamente, mas Lia nunca desejando estar presente. A disponibilidade da família revela toda a intenção em colaborar, valorizando esses encontros comigo. No entanto, a cada novo encontro, cerca de quatro ou cinco ao longo desses seis anos de psicoterapia, confirma-se a dificuldade de oferecerem a Lia algo além do que já vem sendo proporcionado, pois cada um encontra-se subjetivamente enovelado em seus próprios problemas.

Sua progressiva incapacitação levou-a à especial necessidade de sustentarse fora e dentro de si, procurando não se perder enquanto sujeito. O trabalho psicoterapêutico vinha fortalecer o sujeito desse corpo que vive seu destino rumo à imobilização. $\mathrm{O}$ caminho regressivo da independência à dependência foi impondo 
a Lia a inclusão de técnicos e cuidadores, que, funcionando como apoio, muitas vezes exerciam a função de ego auxiliar no que ela já não se bastava. Conforme apontado por Winnicott (1990), em vez da ilusão de criar o mundo como um recém-nascido que vai se constituindo como sujeito, Lia sente que a doença lhe rouba a criatividade, consome suas ilusões, esgota seus prazeres e a oprime em um corpo que progressivamente se retrai. A mente lúcida por vezes não resiste e o acompanha, possivelmente fazendo o caminho de volta ao ego corporal dos primórdios da vida, quando o sofrido no corpo é intrínseco na formação do psíquico. "O aparelho psíquico e o organismo são partes de um todo indissociável" (Berlinck, 1999, p. 12).

Conforme apontado pela fonoaudióloga que assiste Lia, muito provavelmente ela é portadora de mal de Parkinson atípico, condição que condena o paciente a apenas uma década de sobrevida, período que se completa por agora. E Lia acabou somando mais essa singularidade, além de sua doença manifesta precocemente e sua rejeição corpórea ao bálsamo-dopamina para os sintomas debilitantes. Quantas questões para nós, psicanalistas, que entre o soma e a psique procuramos nos orientar e desvelar o que pode parecer implacável e indecifrável.

\section{Sobre o mal de Parkinson}

Os progressos da medicina são ainda insuficientes para uma atribuição segura da causa primária da degeneração dos neurônios e da conseqüente falha na produção de dopamina. De acordo com Grossmann (1998), predisposição genética, fatores ambientais e produção de radicais livres têm sido objeto de especial interesse e estudo. "Os sintomas da doença só aparecem quando $70 \%$ a $80 \%$ das células produtoras da dopamina já entraram num processo de degeneração, isto é, já morreram (...) No cérebro, ao contrário do restante do organismo, as células não se renovam" (ibid., p. 43).

Os avanços científicos têm sido enormes nos últimos tempos, incluindo cirurgias e marcapasso cerebral, que, com os medicamentos, visam eliminar sintomas e retardar a progressão dessa doença incurável, embora não fatal. Estudos científicos sobre o emprego de células fetais para implante cerebral têm sido largamente desenvolvidos principalmente nos Estados Unidos, o que se traduz em esperança de tratamento ou até na cura dessa doença que afeta o cérebro, abala a existência, transtorna a subjetividade e impõe constantes desafios.

De acordo com Fujita e Gregório (1988), a doença de Parkinson é uma síndrome neurológica caracterizada pela associação de acinesia (diminuição de movimentos), rigidez muscular, aumento do tônus e tremor. Seu início costuma 
ocorrer na idade madura e velhice, tendo evolução lenta e progressiva. A acinesia é caracterizada pelo apagamento da movimentação do paciente, incluindo-se a mímica facial e os movimentos acessórios. Há grande dificuldade de iniciar movimentos voluntários. A rigidez muscular revela-se na postura encurvada, braços e mãos fechadas. Os movimentos de roda denteada são expressão característica da progressão da doença e a perda de equilíbrio constitui sintoma importante. Os sintomas secundários incluem aumento da salivação, aumento da produção de suor, dores pelo corpo, distorções da fala, somando-se ainda outras complicações decorrentes da doença.

Lia recebe uma medicação antiparkinsoniana (agonista da dopamina), que pode ser tolerada sem as reações adversas de náusea e vômito que lhe provoca a levodopa ou L-dopa. Antes mesmo de iniciar a psicoterapia, Lia já vinha sendo medicada com antidepressivo, recentemente tendo sido administrado medicamento ansiolítico para melhorar seu sono (dificuldade de dormir toda a noite e voltar a dormir depois de acordar, sintomas comuns em pessoas com o mal de Parkinson). No entanto, o ansiolítico parece ter contribuído para que Lia permanecesse menos disposta durante a vigília, o que fez com que fosse suprimido.

Ultimamente, quando Lia tem dificuldades para voltar a dormir, pensa constantemente em "como seria a morte". Ao me comunicar isso, o choro sobrevém e seu sofrimento encontra cada vez menos possibilidades de se exprimir em palavras. Seu olhar solicita que eu a poupe de ter de falar o que se revela em lágrimas e contrações de seu corpo debilitado.

Há algum tempo, Lia apresenta disfagia (dificuldade de deglutir ou engolir) e freqüente obstipação (constipação ou prisão de ventre). A dificuldade de controle esfincteriano há muito obriga Lia a recorrer ao uso de fraldas descartáveis. Por vezes, retenções urinárias promovem infecções e Lia tem de receber sonda. A dificuldade de locomoção fez com que Lia usasse bengala, andador e finalmente cadeira de rodas. A dificuldade de movimentos faz com que atualmente tenha de contar com ajuda para sua higiene pessoal, alimentação e até mesmo para virarse na cama. A contratação da assistente de enfermagem foi um dos momentos críticos para Lia, conferindo a própria incapacidade diante dos hábitos e cuidados pessoais mais elementares.

As atividades de lazer e viagens sempre foram de muita importância para Lia, mas veio se sentindo progressivamente desestimulada a realizá-las. Abalada a cada nova frustração diante das dificuldades enfrentadas, Lia terminou por renunciar a atividades que sempre lhe deram prazer: "O Parkinson me tirou todos os prazeres: de comer, de beber, de andar, de escrever, dirigir, de dançar, de me divertir, de viajar, de fazer todas as coisas por mim mesma".

Além do mais, sente-se muito sensível à reação das pessoas que a cercam. Antes de uma reunião que eu faria com sua família anos atrás, Lia me fez men- 
sageira: "Desejo que as pessoas da família sejam mais compreensivas, mais tolerantes, mais pacientes e mais afetivas". Esta acabou sendo uma expectativa constante de Lia, constatando que para alguns dos seus era extremamente difícil incorporá-la como alguém limitada pela doença, em que os mais simples automatismos deixam de ocorrer não por mera preguiça ou falta de esforço pessoal.

A reabilitação física ocupa papel importantíssimo no tratamento da doença de Parkinson. "Métodos terapêuticos auxiliares, incluindo fonoaudiologia, fisioterapia e terapia ocupacional, além de aspectos nutricionais, não escapam à sua avaliação e ocupam merecido espaço recheado de conselhos práticos" (Fujita e Gregório, 1988, p. 14). Embora amplamente reconhecido que cada caso de mal de Parkinson nunca é idêntico a outro, no atendimento multidisciplinar necessário para melhorar a qualidade de vida do paciente e sua convivência com a doença, a subjetividade do paciente pode permanecer em menor destaque em face da florescência dos sintomas físicos.

Atualmente, Lia realiza sessões semanais de fonoaudiologia e de fisioterapia. Há recomendação de exercícios diários, tarefa que fica a cargo de sua assistente de enfermagem. "A reeducação permite lutar contra a tendência ao recolhimento em si, tentação quase constante da doença, permitindo continuar ou retomar atividades voltadas para o mundo externo" (Grossmann, 1998, p. 87).

$\mathrm{O}$ aumento do tremor é diretamente influenciado por reações emocionais, fadiga ou esforços mentais, segundo Fujita e Gregório (idem). A tensão e o nervosismo influem diretamente na voz e na fala; os músculos da garganta, do pescoço e da face, ao contrair-se, limitam a vibração correta e livre das pregas vocais, conforme Grossmann (idem). O paciente necessita fazer um esforço consciente para falar claramente e não deixar os outros falarem por ele, valorizando a comunicação.

Desse modo, Lia veio encontrando nos últimos tempos crescentes dificuldades para se comunicar. Além da emoção que toma conta de sua fala, o choro que irrompe insistente e o fato de não ser ouvida a não ser quando o ambiente está bastante silencioso e a atenção integralmente voltada para ela contribuíram para que se calasse cada vez mais. O grande prazer da convivência e participação social reduziram-se, e Lia atingiu um estado de progressivo isolamento, não mais se esforçando para se comunicar com os demais, como fazia outrora.

O atendimento psicoterapêutico foi a oportunidade que Lia criou para si há anos para que fosse escutada em sua vivência singular, valorizando a experiência de criar palavras para falar de sua dor. Anteriormente, essa dor se expressava fundamentalmente pelo choro sentido, alvo de atitudes de consolo e carinho que não conseguiam transformar a dor do vivido. 


\section{Cuidados terapêuticos}

Quando comecei a atender Lia em psicoterapia, seu estado permitia um atendimento relativamente convencional. Gradativamente, essa condição foi se modificando, e, portanto, deixou de ser uma promessa de analisá-la, na acepção do termo em psicanálise. Via-me em uma condição não programada e não delimitada diante de uma paciente a quem tinha o objetivo de ajudar, principalmente identificando as necessidades que apresentava, conforme apontou Khan (1991). Nos últimos tempos, talvez esse atendimento pudesse ser mais adequadamente descrito como "cuidado psicoterapêutico", conforme designação desse autor, com base nos ensinamentos de Winnicott. São atendimentos que se distinguem da chamada análise. O trabalho interpretativo é restringido para dar lugar ao cuidado, o que envolve inevitavelmente a família e, por vezes, amigos ou pessoas das relações do paciente. Por vezes, os pacientes podem estar "precisando mais urgentemente de cuidado terapêutico do que de insights" (ibid., p. 87).

$\mathrm{O}$ tipo de psicoterapia deve estar estreitamente vinculado às necessidades do paciente. Um analista treinado pode fazer outra coisa de modo bastante proveitoso que não seja análise. "Se o paciente não necessita de análise então eu dou alguma outra coisa" (Winnicott, 1965, p. 166).

E no dizer de Khedy (1995), para Winnicott uma análise é especial quando demanda uma provisão ambiental adaptativa, o que exige do terapeuta toda a sua capacidade criativa. E são essas análises especiais que diferenciam os analistas. "São sempre um desafio que nos obrigam a lidar com frustrações e a tolerar feridas narcísicas. Porém nos gratificam muito, na medida em que sentimos que, sem sermos gênios, somos capazes de criar e de vivermos relações muito originais" (ibid., p. 98).

Lia sempre nutriu especial interesse por informações sobre sua doença, procurando atualizar-se a respeito dos avanços científicos e refletir sobre os depoimentos de parkinsonianos de destaque. Em momentos mais esperançosos, serviam como modelo e estímulo, em momentos mais depressivos apontavam para um destino em face do qual Lia sentia esgotar suas forças. No entanto, ao longo de todos esses anos Lia veio se mostrando uma batalhadora quase incansável. Embora inicialmente enfrentasse as incapacitações progressivas com dor e por vezes revolta, ao final redirecionava forças de modo que incorporasse as limitações e tentava erigir para si uma vida com sentido.

Lia freqüentava aulas de ioga pouco depois de iniciarmos a psicoterapia e posteriormente passou a contar com um professor de informática. Se suas pernas a detinham, era seu desejo correr mundo pela Internet, escrever e-mails para os primos do estrangeiro. Em algumas festas, Lia chegava a puxar o marido para 
dançar, elegantemente trajada em vestido longo, mesmo que nessas ocasiões suas pernas não pudessem acompanhar o saltitar do coração.

Ir ao cinema sempre foi um grande acontecimento, mesmo que tivesse de assistir ao filme na cadeira de rodas e enfrentasse as dificuldades de acesso à sala de projeção. A vaidade de Lia sempre fez com que cuidasse de sua aparência, mesmo quando veio a necessitar de ajuda até para passar batom nos lábios.

Há cerca de três anos, após muitas dúvidas e ambivalência, Lia decidiu que havia chegado a hora de ir à Associação Brasil Parkinson. Sua participação em aulas de pintura lhe rendeu alguns trabalhos, que tempos depois fizeram parte de bela exposição comunitária em espaço cultural de um grande banco. O orgulho de Lia sobrepunha-se à timidez pela qualidade artística, que sentia ser menor do que desejaria. No entanto, em seus alegres desenhos, incluiu um belo arco-íris, evidenciando cores em seu horizonte. Essa era Lia havia cerca de dois anos.

Assim foi até meses atrás. A cada Natal saía em busca de presentes, em diversos passeios pelo shopping. Assim foi nas eleições presidenciais no final de 2002, quando compareceu para votar em urna eletrônica, recebendo incentivos e cumprimentos da enorme fila de pessoas que a viram chegar empurrada na cadeira de rodas. Feliz por ali estar e orgulhosa em assim se expressar, não apenas como cidadã, mas fundamentalmente como sujeito.

\section{Depressão e corpo combalido}

A psicoterapia foi o espaço de escuta que Lia manteve ao longo destes últimos seis anos, não chegando a interrompê-lo mesmo nos momentos mais críticos. Sua família reconhece nesse vínculo terapêutico o suporte emocional indispensável por todos estes anos. Acompanhada por um dos filhos, pelo marido, pela irmã ou por sua assistente de enfermagem, Lia chegou a faltar apenas excepcional e justificadamente. $\mathrm{O}$ atendimento domiciliar só foi necessário por algumas semanas, ocasião da recuperação pela cirurgia palidotomia anos atrás. Apesar de tudo, nos últimos meses veio se intensificando o estado depressivo de Lia, concomitante a um agravamento de seus sintomas físicos.

(...) é impossível estabelecer uma causalidade unívoca, emocional, orgânica ou exógena para a compreensão da dinâmica do adoecer (...) Qualquer sintoma, mental ou somático, é, antes de tudo, uma manifestação do sofrimento do sujeito, uma demanda oriunda das marcas de seu desamparo mais fundamental e inevitavelmente dirigido para o outro. Independentemente de sua etiologia ou de sua forma, o sintoma e a doença são por eles mesmos perturbadores do equilíbrio da economia psicossomática, pela ameaça que eles representam para a integridade 
do indivíduo, podendo promover ou alimentar o torvelinho regressivo, e mesmo intensificar uma desorganização (Volich, 2002, p. 166).

A vivência de Lia pode ser entendida como expressão do protótipo infantil do estado de desamparo terrificante em crianças de tenra idade, "lembrança da própria infância e da infância da raça humana (...) contra os perigos da natureza e do Destino, e contra os danos que o ameaçam (o homem) por parte da própria sociedade humana" (Freud, 1927, p. 30). Lia revive esse estado particularmente durante as noites em que permanece desperta por horas seguidas, sem conseguir conciliar o sono nem chamar alguém que possa vir ajudá-la a enfrentar a angústia vivida. "Aquele que dorme pode ser tomado por um pressentimento da morte, que ameaça colocá-lo no túmulo" (ibid., p. 28).

Há na depressão, na dor e na angústia sensações que incidem espetacularmente no corpo, mas que são sempre psíquicas e que são inscrições do tempo na carne do humano, frágil e desamparada, que solicita constantes cuidados que atestam a insuficiência diante de ameaças que colocam a existência em permanente perigo (...) a depressão, a dor e a angústia são mecanismos de defesa contra ameaças vindas tanto de fora quanto de dentro do human (...) são sensações referidas ao desamparo que é humanamente extenso (Berlinck, 1999, p. 10).

Lia vem enfrentando seu destino com a perplexidade de quem não encontra explicação possível e suficiente para o mal que a atinge, o que anos atrás fez com que fosse em cadeira de rodas ao Vaticano, buscando amparo e consolo na benção de Sua Santidade o papa. A foto desse encontro me foi mostrada com o júbilo de quem comemorava ter ido beber na fonte máxima de suas esperanças.

Entretanto, mais recentemente, Lia me relatou em meio a grande emoção: "O papa deu uma declaração em que reconheceu que por estar com mal de Parkinson avançado estaria chegando o momento de ir se reunir a Deus". A desesperança sobreveio, o choro de Lia mal conseguia contar sobre a magnitude de sua dor, angústia e desamparo. Alguém que conseguira meses antes vencer uma séria inapetência, retomando em parte a absorção de alimentos que traziam vida para dentro de si, agora voltava a se render a seu destino humano. Para tanto, seu enrijecimento muscular começou a travar-lhe mais intensamente os maxilares, e a deglutição de alimentos pastosos ficou cada vez mais dificultada.

“A opção de viver cria a opção de morrer (...)" (Grossmann, 1998, p. 21).

Em estado depressivo acentuado, Lia iniciou um período em que sua ligação com o mundo exterior começou a se afrouxar, aumentando o ensimesmamento em um interior povoado de sombras e ameaças, em que a morte começou a ser sentida como irremediavelmente próxima. Lia parecia querer paralisar seus fantasmas, mas o que apenas conseguia era imobilizar seu corpo e restringir algumas funções vitais. Assim, pouco podia sair de si pela fala, e quase nada podia 
entrar em si como nutriente para um corpo arcado pela doença e pelo recolhimento libidinal - seus laços com a vida enfraqueciam-se a passos largos.

Segundo Safra (2002), o gesto revela o vivido e, no caso de Lia, o olhar que não mais se sustenta em direção ao outro tudo resume. Parece sentir-se cercada por pessoas que não conseguem alcançar a magnitude de seu embate com a angústia original, a do aniquilamento.

O desinteresse, a apatia, a inapetência pela vida revelam a enorme solidão desse percurso pessoal. Em seu estado atual, Lia parece retornar à condição de solidão essencial, indicando estar perdida em seu interior "a capacidade da pessoa saudável de estar a sós e se fazer cuidar por uma parte do self especialmente destacada para tomar conta do todo" (Winnicott, 1990, p. 154).

Safra (2002) ressaltou que a morte do ser humano implica em se despedir, sair do mundo do humano. Não se trata apenas de um acontecimento biológico, é uma aquisição de si mesmo. A todo o momento na vida, uma pessoa estaria iniciando e acabando, sempre colocando as questões sobre sua origem e sobre seu fim. Faz parte de sua singularização enquanto sujeito e a forma como se posiciona em face do que pode ser sua questão originária, que o constitui e constitui um sentido da vida.

Se o choro de Lia protesta e implora, o olhar trespassado inunda quem dela se aproxima com a impotência de ação diante de um destino sentido como implacável. Quando o desejo de viver se rende desse modo, o narcisismo se articulando com a pulsão de morte, parece entrar em cena o que Green (1983) propõe denominar narcisismo negativo. Lia transmite contratransferencialmente seu cruel e doloroso impasse: por um lado que eu a auxilie a se salvar e por outro que a deixe ir, passageira esgotada de uma vida que lhe foge a cada momento. E aí parece imprescindível ao psicanalista "aceitar reconhecer esta implacável armada das sombras - os poderes da morte - que solapa suas tentativas terapêuticas" (ibid., p. 11).

Ao me deparar com Lia em seu silêncio, cada vez mais confiro que "Conhecer o próximo significa rastreá-lo nas trilhas de origem das próprias experiências corporais, sensações e imagens motoras (...) vivências no corpo, que ocorrem apenas em estado de sofrimento, da dor do anseio" (Berlinck, 1999, p. 31). É com a ressonância dessa dor em mim que posso dimensioná-la em Lia.

Verifico o valor das palavras de Fédida (2002) a reforçar a visão de Winnicott e seu seguidor Masud Khan, quando insistiam sobre a importância do holding dos pacientes deprimidos, o ambiente material e a modalidade de presença do analista proporcionando a possibilidade de o paciente descobrir o humano em relação ao "não-humano" de seu fechamento deprimido (ibid., p. 158).

É quando qualquer vínculo parece se desfazer e nenhum horizonte de fala e de rosto subsiste, que se pode, de fato, falar de depressão. A experiência do 
desumano encontra-se nesse retraimento que torna o rosto imóvel e mudo, não sabendo mais nem mesmo experimentar o que significa um olhar ou um gesto do outro (...) a maior dificuldade consiste em construir um espaço para a comunicação psíquica e para devolver a vida - pouco a pouco e lentamente - a um vivente inanimado (...) o próprio estado deprimido tem de se confrontar: $a$ glaciação da fala humana (ibid., p. 177).

Uma das primeiras particularidades da depressão não é justamente privar o sujeito da linguagem elementar para expressar seus afetos (...) Em sua presença silenciosa junto ao doente, cabe ao analista encontrar as condições sensoriais de uma recepção singular dos afetos elementares e de formar em si - por meio de impressões e de imagens - as palavras de sua denominação (...) Se falamos de vivência do abandono e da perda no deprimido, ainda faltaria acrescentar que esta experiência completamente primitiva é entendida como impotência de contato, na origem do psíquico (ibid., p. 43).

Pelo processo que ela desencadeia e pela situação que instaura, a psicoterapia analítica constitui exatamente uma reanimação desse vivente psíquico inanimado. Ela consiste em restituir ao sujeito deprimido sua capacidade depressiva e, assim, sua criatividade psíquica (...) é do interior que se abre o processo de cura. E é preciso ser dois para que esse processo ocorra (ibid., p. 16-7).

Conforme destacado em reunião técnica recentemente realizada com a fonoaudióloga e a fisioterapeuta que acompanham Lia, no estado de saúde em que se encontrava nos últimos tempos, poderia aspirar alimentação em seus pulmões e isso provocar um quadro de pneumonia. E foi efetivamente esse o fator determinante que a levou dias atrás à internação hospitalar e até a UTI, onde se encontra em lenta recuperação.

Como psicanalista, no momento aguardo (im)pacientemente verificar se ainda me será possível alguma ação na situação-limite em que Lia se encontra, enfrentando a luta pela vida em estado que por vezes me faz crer que já se encontra vencido pela morte.

\section{Referências}

Berlinck, M. T. (org.). A dor. In: Dor. São Paulo: Escuta, 1999.

FÉdidA, P. Dos benefícios da depressão: elogio da psicoterapia. São Paulo: Escuta, 2002.

Freud, S. (1927). O futuro de uma ilusão. Rio de Janeiro: Imago, 1969.

Fujita, K. \& Gregório, B. L. Neurofisiologia para psicólogos. São Paulo: EPU, 1988.

GreEn, A. Narcisisme de vie - Narcisisme de mort. Paris: Minuit, 1983.

Grossmann, M. Com Parkinson e de bem com a vida: a experiência de uma parkinsoniana. São Paulo: Lemos Editorial, 1998. 
KHAN, M. M. R. Quando a primavera chegar. São Paulo: Escuta, 1991.

KHedy, S. O setting e as análises especiais. In: Mello Filho, J. \& Silva, A. L. M. L \& COL. Winnicott 24 anos depois. Rio de Janeiro: Revinter, 1995.

SAfrA, G. Aspectos da constituição do self: o gesto na tradição. Palestra realizada no Instituto Sedes Sapientiae pelo Departamento Formação em Psicanálise, nov./2002.

Volich, R.M. Psicossomática. São Paulo: Casa do Psicólogo, 2002.

Winnicott, D.W. The Maturational Processes and The Facilitating Environment. London: The Hogath Press, 1965.

Tudo começa em casa. São Paulo: Martins Fontes, 1989.

Natureza humana. Rio de Janeiro: Imago, 1990.

\section{Resumos}

La enfermedad de Parkinson es un síndrome neurológico de evolución lenta y progresiva que surge en la edad madura y la vejez. El creciente debilitamiento físico contrasta con el mantenimiento de la integridad mental, que en la mayoría de los pacientes se da hasta el fin de la vida. En esta enfermedad incurable, que suele prolongarse muchos años, surgen importantes reacciones psíquicas frente a la progresiva pérdida de capacidades, que se reflejan profundamente en la subjetividad del paciente. Este trabajo se refiere a la atención de una paciente, acompañando su proceso de concientización y elaboración de la irreversibilidad de la enfermedad. Al final, se resalta la intrínseca articulación somático-psíquica, destacándose la depresión debido a la acentuación de los síntomas parkinsonianos.

Palabras claves: Enfermedad de Parkinson, depresión, subjetividad, psicoterapia no-convencional

La maladie de Parkinson est un syndrome neurologique d'évolution lente et progressive et qui se manifeste à l'âge mûr et à la vieillesse. La faiblesse physique croissante contraste avec le maintien de l'intégrité mentale jusqu'en fin de vie chez la plupart des patients. Au cours des longues années que dure cette infirmité incurable, d'importantes réactions chimiques se manifestent face au handicap progressif générant des effets profonds sur la subjectivité du patient. Ce travail porte sur la prise en charge d'une patiente et accompagne son processus de prise de conscience et d'élaboration de l'irréversibilité de la maladie. En conclusion, l'articulation somato-psychique intrinsèque est soulignée, l'accent étant mis plus particulièrement sur la dépression lorsque les symptômes de la maladie de Parkinson se font plus aigus.

Mots clés: Maladie de Parkinson, dépression, subjectivité, psychothérapie non-conventionnelle 
Parkinson's disease is a neurological syndrome of slow and progressive evolution that affects people in maturity and old age. Growing physical weakness contrasts with the maintenance of mental integrity until the end of life in most patients. This incurable disorder, which frequently lasts for years, is characterized by important chemical reactions in view of the individual's progressive incapacity and serious consequences in his or her subjectivity. This article is about a patient we treated and the follow-up of her process of awareness and working out of the irreversibility of her disease. We also underscore the intrinsic somatic-psychological articulation, especially depression, when symptoms become more severe.

Key words: Parkinson's disease, depression, subjectivity, non conventional psychotherapy 